\title{
Meios Autocompositivos de ResoluçÃo de CONFlitos COlETIVOS: REFLEXÕES SOBRE A ADEQUAÇÃO DA TÉCNICA EM FAVOR DA EFETIVIDADE
}

\author{
Tereza Cristina Sorice Baracho Thibau* \\ Ludmila Costa Reis**
}

1 Introdução. 2 Mediação, conciliação ou negociação em conflitos coletivos. 3 A construção do consenso: técnica ou utopia? 4 Espécies de conflitos coletivos e a adequação da técnica. 5 Conclusão. Referências.

\section{RESUMO}

O presente artigo propõe-se a analisar as normas que disciplinam os meios autocompositivos de resolução de conflitos no direito brasileiro e confrontá-las com a sua possibilidade de aplicação aos conflitos coletivos. Busca-se problematizar a aplicação das técnicas de conciliação, negociação e mediação às diversas espécies de conflitos, tendo em vista seus traços distintivos. Pretende-se demonstrar que, diante das características inerentes aos conflitos coletivos, impõe-se a busca por soluções técnicas adequadas, sob pena de comprometimento dos resultados consensuais almejados. Assim, apresenta-se a mediação como meio autocompositivo potencialmente adequado para a resolução de conflitos coletivos, desde que seja considerada a necessidade de adequação da técnica às peculiaridades apontadas.

Palavras-chave: Solução de conflitos. Meios autocompositivos. Conflitos Coletivos.

\section{INTRODUÇÃO}

A ênfase nos meios alternativos ou adequados de resolução de conflitos está em voga no direito brasileiro. Não apenas em razão da cultura consensual propagada pela Resolução ${ }^{\circ}$ 125/10 do Conselho Nacional de Justiça, e, mais

* Professora da Faculdade de Direito da Universidade Federal de Minas Gerais. Atual Vice Diretora da Divisão de Assistência Judiciária da Faculdade de Direito da Universidade Federal de Minas Gerais. Doutora em Direito pela Universidade Federal de Minas Gerais. Mestre em Direito pela Universidade Federal de Minas Gerais. Graduação em Direito pela Universidade Cândido Mendes Ipanema. E-mail: <tthibau@gmail.com>.

** Doutoranda em Direito pela Universidade Federal de Minas Gerais. Mestre em Direito pela Universidade Federal de Minas Gerais. Especialista em Administração Pública pela Pontifícia Universidade Católica do Estado de Minas Gerais. Graduada em Direito pela Universidade Federal de Minas Gerais. E-mail: <ludmilareis@hotmail.com>. 
recentemente, pela Resolução n ${ }^{\circ}$ 118/14 do Conselho Nacional do Ministério Público, pela Lei n ${ }^{\circ}$ 13.140/15 (Lei de Mediação) e pelo Novo Código de Processo Civil (Lei $\left.n^{\circ} 13.105 / 15\right)$, mas, sobretudo, em razão do contexto fático-jurisdicional que deu ensejo a toda essa gama de inovações normativas. Em verdade, a percepção do cidadão jurisdicionado, dos operadores do direito e dos estudiosos do sistema de justiça em geral já há muito constatou: o acesso ao sistema judicial não se traduz em sinônimo de acesso à justiça.

Diversos fatores são comumente apontados como causas dessa insuficiência, tais como excesso de demandas, número insuficiente de profissionais, inadequação da legislação processual, cultura social do litígio, formação acadêmica essencialmente adversarial dos bacharéis em direito, dentre outros. Nesse mesmo contexto é que a ciência do direito processual coletivo também encontrou campo fértil para o seu desenvolvimento, apresentando soluções técnico-processuais que pudessem reduzir o número de ações propostas, beneficiar o maior número de pessoas possíveis atingidas pela mesma situação fática e reduzir a insegurança jurídica decorrente da possibilidade de decisões contraditórias.

Contudo, a inexistência de órgãos jurisdicionais especializados no julgamento das ações coletivas ${ }^{1}$ fez que tais procedimentos coletivos consubstanciassem "mais um" nas prateleiras das secretarias e nas mesas dos magistrados, recebendo tratamento de priorização jurisdicional, na prática, quase equivalente às demandas individuais. E não sem razão, pois, na prática, disputam o status de prioridade com ações individuais que versam sobre alimentos, família, saúde, meio ambiente, direitos do idoso e da criança e do adolescente, fazenda pública, dentre outros. Passando-se a considerar as inúmeras comarcas de varas únicas pelo país, as ações cíveis urgentes ainda concorrem, em prioridade, com os processos criminais de réus presos e feitos relacionados à violência doméstica.

$\mathrm{Na}$ tentativa de estabelecer alguma diferenciação ou regra de priorização de trâmite e julgamento, o CNJ passou a estabelecer, a partir do ano de 2014, metas direcionadas a tais espécies de ações. ${ }^{2}$ A necessidade de estabelecimento de tais metas autoriza uma conclusão inexorável: a eficiência na prestação jurisdicional buscada por meio da técnica processual coletiva também encontrou as mesmas dificuldades de tramitação identificadas nas demandas individuais. Assim, no ano de 2016, novas metas foram estabelecidas em favor da celeridade no julgamento daquelas ações, ${ }^{3}$ constituindo verdadeira política pública visando ao aprimoramento da duração da prestação jurisdicional.

Conclui-se, até este ponto, que as mesmas razões que ensejaram a busca por meios extrajudiciais e consensuais de resolução de conflitos para as pretensões individuais também são válidas para as pretensões coletivas. Contudo, as soluções até então apresentadas, ao menos em âmbito normativo, não atendem às peculiaridades dos conflitos que envolvem interesses coletivos.

Com efeito, a Resolução no 125/10 do Conselho Nacional de Justiça 
apenas regulamenta os centros de mediação e conciliação a serem instalados nos juízos e tribunais e faz breve referência à possibilidade de incentivo às mediações comunitárias, sem esclarecer do que se trata ou da forma como ocorreriam. Além disso, a citada resolução estabeleceu princípios e regras para mediação e conciliação aplicáveis, conforme previsto, às áreas empresarial, familiar, civil (consumerista, trabalhista, previdenciária etc), bem como à área penal e à justiça restaurativa. ${ }^{4}$

Por seu turno, a Resolução $n^{0} 118 / 14$ do Conselho Nacional do Ministério Público refere-se ao uso da mediação para conflitos bilaterais e ainda estende a sua possibilidade para as mediações comunitária e escolar, sem especificar como seria a técnica aplicada em cada uma das hipóteses. Além disso, deixou de considerar todas as outras hipóteses de conflitos de natureza coletiva e complexa, com múltiplas partes, nas quais o procedimento da mediação também poderia ser empregado. Ao mesmo tempo, a citada Resolução previu o instrumento da negociação para as controvérsias ou conflitos em que o Ministério Público possa atuar como parte na defesa de direitos e interesses da sociedade, em razão de sua condição de representante adequado e legitimado coletivo universal. Poder-se-ia concluir, portanto, à luz de tais regras, que a mediação e a negociação cumpririam papéis distintos e estanques nos conflitos coletivos.

A Lei $n^{\circ} 13.140 / 15$ já estabelece, em seu preâmbulo, que se destina à mediação entre particulares como meio de solução de controvérsias. Por sua vez, o Novo Código de Processo Civil destina-se a regular os procedimentos de ações judiciais individuais e, apenas subsidiariamente, às ações coletivas. Ressalte-se que o único artigo que tratava, de alguma forma, das ações coletivas (artigo 333) foi vetado.

Assim, verifica-se que, embora haja uma legislação consolidada no Brasil destinada a regulamentar a resolução dos conflitos coletivos pela via judicial - o denominado microssistema de tutela coletiva constituído em especial pela parte processual do Código de Defesa do Consumidor e pela Lei de Ação Civil Pública -, verifica-se que ainda não há uma clareza, seja normativa seja doutrinária, quanto aos procedimentos e técnicas que podem ser utilizados na via extrajudicial para se alcançar uma solução autocompositiva do conflito coletivo. E nem se diga que tal técnica ou procedimento seria o termo de ajustamento de conduta, uma vez que tal instrumento consubstancia apenas um meio de formalização do acordo, e não uma técnica de como se chegar ao acordo.

Diante dessa lacuna normativa e doutrinária, cumpre-se indagar quais técnicas autocompositivas poderiam ser empregadas para buscar soluções consensuais nos conflitos coletivos, sem perder de vista as particularidades inerentes a tais espécies de conflitos. É nesse contexto que se faz necessário o estudo e a análise dos exemplos do direito comparado.

Nos Estados Unidos, a popularização dos denominados ADR - Alternative 
Dispute Resolution, ou meios alternativos de resolução de conflitos, iniciou-se na década de 60 a partir de um esforço de expansão das técnicas autocompositivas das relações de trabalho para as relações da comunidade. Aponta-se que, em meados dos anos 70, o procedimento de mediação foi aplicado em uma questão ambiental, provavelmente pela primeira vez, relacionada à proposta de uma construção de barragem no Rio Snoqualmie, no estado de Washington. Nas décadas seguintes, observou-se que a aplicação da mediação a questões que envolvem largo interesse público se institucionalizou nas agências e órgãos públicos americanos, substituindo o processo judicial. ${ }^{5}$ Desde então, a forma mais comum de mediação no setor público norte-americano tornou-se a mediação ambiental, o que se refletiu na vasta produção de trabalhos acadêmicos sobre o tema. ${ }^{6}$ De fato, a mediação ambiental é comumente tratada, naquele país, como sinônimo de mediação no setor público ${ }^{7}$. Em alguns casos, os mediadores em questões ambientais se engajam em atividades que se traduzem em capacitação das partes, métodos de participação pública e mediação propriamente dita. ${ }^{8}$ Por outro lado, em se tratando de conflitos que se referem a interesses individuais, defende-se uma técnica mais "pura" de mediação, na qual o terceiro, considerado imparcial, apenas auxilia que as partes, por si, cheguem a um consenso.

\section{MEDIAÇÃO, CONCILIAÇÃO OU NEGOCIAÇÃO EM CONFLITOS COLETIVOS}

Os métodos voluntários e autocompositivos de resolução de conflitos, tais como a mediação, a conciliação e a negociação, conferem às partes a oportunidade de moldar o procedimento, participar ativamente do resultado, revelar ou descobrir interesses ao invés de posições, despender menos recursos para resolver o conflito e acelerar a sua solução, transformar as relações e promover soluções que melhor atendem às suas necessidades.

Não há dúvidas de que os instrumentos utilizados para a busca de consensos ou acordos entre particulares, titulares de direitos individuais, também podem ser empregados para o alcance do mesmo objetivo entre titulares de direitos coletivos ou seus representantes adequados (no caso do direito brasileiro, estabelecidos pela lei) e as partes que porventura os tenham violado ou ameaçado violar.

O novo Código de Processo Civil pouco contribui para diferenciar as técnicas de conciliação e mediação. Pelo que se depreende das disposições legais, em especial dos parágrafos segundo e terceiro do artigo 165, a distinção principal consistiria na possibilidade de o terceiro imparcial propor ou não soluções para o conflito. O conciliador poderia fazê-lo, ao passo que ao mediador incumbiria estimular que as partes identificassem por si as soluções. Além disso, ao estabelecer que a conciliação se dará preferencialmente nos casos em que não houver vínculo anterior entre as partes e que a mediação, por seu turno, seja aplicada preferencialmente quando houver esse vínculo anterior, extrai-se que o objetivo maior da conciliação é a obtenção do acordo, e o da mediação é a preservação do vínculo existente entre as partes, preservando-se a comunicação entre estas. 
O ato de conciliação, seja em juízo seja extrajudicialmente entre as partes, pode ser considerado, sob o ponto de vista procedimental, o mais simples dentre os instrumentos autocompositivos, uma vez que não se lhe impõem regras. Trata-se, em verdade, de ato corriqueiro das relações humanas, apropriado pelo Direito como espécie dos meios autocompositivos. Na prática, dentro ou fora do Poder Judiciário, a conciliação se traduz em uma conversa informal entre as partes com o objetivo de findar, ou ao menos reduzir, um conflito de interesses juridicamente tutelados, com o auxílio de um terceiro imparcial.

A negociação, por seu turno, trata-se de procedimento autocompositivo oriundo, majoritariamente, das práticas e acordos comerciais, de cunho estritamente patrimonial. É um dos métodos mais difundidos nos Estados Unidos, sobretudo após a publicação do disseminado livro Getting to Yes, de William Ury e Roger Fisher. ${ }^{9}$ O renomado Programa de Negociação de Harvard, constituído entre uma parceria dessa universidade com o Massachussets Institute of Tecnology (MIT), é um dos principais responsáveis pela reprodução e desenvolvimento das ideias originariamente concebidas na obra citada. Apesar de estar sediado na Faculdade de Direito de Harvard, o referido Programa contempla cursos de interesse de diversas áreas do conhecimento e profissionais, sobretudo de administradores de empresas, vendedores e gestores públicos e privados. ${ }^{10}$

Nos casos de tentativa de conciliação ou negociação, o pressuposto indispensável para a obtenção de um consenso satisfatório - sob o ponto de vista do sentimento de justiça experimentado pela parte de que se tenha alcançado, de fato, o melhor acordo possível - é a garantia de equilíbrio de representação e poder de negociação entre as partes à mesa. Caso tal garantia não seja alcançada, os referidos instrumentos não se revelam, a priori, a melhor forma de acesso à justiça.

O novo Código de Processo Civil (Lei no ${ }^{0} 13.105 / 15$ ) não prevê a negociação como um instrumento próprio de busca de consenso. Em seu art. $166, \S 3^{\circ}$, admite a aplicação de técnicas negociais com o objetivo de proporcionar ambiente favorável à autocomposição. A opção do legislador em excluir, da codificação da legislação processual civil, a negociação como instrumento próprio de obtenção de acordo parece decorrer do fato de que tal procedimento normalmente ocorre fora das instâncias do Poder Judiciário, antes que as partes procurem o órgão jurisdicional, ou mesmo após, durante a tramitação do processo. Contudo, a referida exclusão em nada afasta a aplicação do procedimento de negociação às fases da conciliação ou mediação, sobretudo diante da liberdade procedimental prevista no $\S 4^{\circ}$ do citado artigo. ${ }^{11}$

Assim, estabeleceu-se uma espécie de fungibilidade entre os instrumentos autocompositivos, com o intuito de adaptá-los às características dos conflitos e garantir maior eficácia na obtenção da solução consensual.

Mas qual procedimento se revela, em verdade, mais adequado à busca de consensos em conflitos coletivos? Neste ponto, também não se pode perder 
de vista qual a espécie de interesse coletivo envolvido e quais são os representantes de tal interesse.

A princípio, não se concebe, por exemplo, no âmbito dos meios autocompositivos, que uma pretensão que visa a concretizar direitos individuais homogêneos ou direitos coletivos stricto sensu seja satisfeita por meio da obtenção de um consenso de cujo procedimento os próprios titulares dos direitos individuais não hajam participado de alguma maneira, uma vez que as características inerentes à titularidade não perdem a sua importância em virtude do tratamento de repercussão coletiva dado à questão. Além disso, há que se ter a participação do representante, de fato ou de direito, da classe, grupo ou categoria de pessoas envolvidas na relação jurídica conflituosa. No que se refere aos direitos difusos, embora os titulares sejam indetermináveis, a legislação brasileira atribui a determinados órgãos e entes públicos a legitimidade para firmar acordos em nome da coletividade (art. $5^{\circ}, \S 6^{\circ}$, da Lei $n^{\circ} 7.347 / 85$ ). Contudo, em se tratando de um procedimento consensual sobre a forma de se chegar a tal acordo, tem-se como desejável a participação de representantes da sociedade civil organizada, pessoas físicas afetadas, conselhos de políticas públicas e outros órgãos públicos, além daqueles formalmente legitimados para a adoção de providências em juízo.

Verifica-se, portanto, que a legitimidade para participar do procedimento autocompositivo do conflito coletivo nem sempre coincide com a legitimidade ativa processual conferida pela lei para veicular a pretensão coletiva em juízo. Cumpre-se, nesse contexto de pluralidade de participantes, identificar qual é o procedimento que se revela mais adequado para buscar a autocomposição, sobretudo quando se tem em vista a natureza complexa e de maior abrangência dos interesses envolvidos.

No Brasil, a Resolução ${ }^{\circ} 118$, de $1^{\circ}$ de dezembro de 2014, do Conselho Nacional do Ministério Público, estabeleceu a previsão de que a negociação é aplicável às controvérsias ou conflitos em que o Ministério Público possa atuar como parte na defesa de direitos e interesses da sociedade, em razão de sua condição de representante adequado e legitimado coletivo universal. Assim, por meio da referida resolução, estendeu-se a possibilidade de aplicação da técnica da negociação aos conflitos coletivos. Contudo, conforme destacado acima, embora o Ministério Público e outros entes e órgãos públicos possuam legitimidade ativa para representarem em juízo, em nome da coletividade, determinados interesses, cumpre-se anotar que, em sede de procedimentos extrajudiciais e consensuais, a participação dos titulares dos interesses representados revela-se não apenas possível, mas, sobretudo, desejável.

Sob essa perspectiva participativa, afirma-se que o procedimento que requer maior reflexão, sob o ponto de vista de sua aplicação aos conflitos coletivos, é o da mediação. ${ }^{12}$ Com efeito, conforme já ressaltado anteriormente, a atual disciplina normativa existente no direito brasileiro sobre a mediação revela-se insuficiente para orientar a sua aplicação aos conflitos coletivos, muito embora 
o procedimento tenha a potencialidade para se traduzir no método autocompositivo mais eficaz quando aplicável a essas espécies de conflitos.

E por que, afinal, a mediação? É o questionamento que orientará o desenvolvimento dos próximos itens.

\section{A CONSTRUÇÃO DO CONSENSO: TÉCNICA OU UTOPIA?}

Em termos gerais, a mediação pode ser definida como um procedimento voluntário no qual uma terceira parte neutra, que não tenha autoridade para impor uma solução, auxilia os participantes a alcançar a sua própria solução para resolver uma disputa ou para planejar uma solução. ${ }^{13}$

Entre os operadores do direito, o procedimento da mediação é comumente pensado como técnica a ser empregada em conflitos envolvendo duas ou até três partes, pessoas físicas ou pessoas jurídicas privadas. Contudo, conforme observou Lawrence Susskind, professor do Departamento de Urbanismo e Planejamento Ambiental do Instituto de Tecnologia de Massachussets (MIT), o mediador pode auxiliar em um variado número de situações envolvendo grande diversidade de partes e questões de significativo interesse público, particularmente antes que uma ação coletiva seja ajuizada. ${ }^{14}$

Nesse contexto, há que se atentar para o fato de que os requisitos para um procedimento de mediação bem sucedida nos conflitos que envolvem múltiplas partes e questões multifacetadas - particularmente nas questões relacionadas às políticas públicas - são significativamente diversos daqueles aplicáveis à mediação envolvendo duas partes, seja antes seja após o ajuizamento de uma demanda judicial.

Observa-se, por exemplo, que nos procedimentos autocompositivos entre particulares, as partes buscam no acordo a solução que seja, obviamente, satisfatória para ambas ou que possam satisfazê-las na melhor medida possível para um acordo. ${ }^{15}$ Nesses casos, os interesses envolvidos, as variáveis, os efeitos, a representação da parte, as regras legais aplicáveis e a forma de execução do acordo são comumente muito claros para ambas as partes. $O$ maior desafio reside mesmo, ou tão somente, no alcance do conteúdo do consenso.

Entretanto, quando se está diante de um conflito complexo - que envolve múltiplas partes, pressupõe a interferência de agências ou órgãos públicos, não está claro em sua extensão e em relação aos interesses atingidos, depende de análise técnica, não apresenta precisão quanto à sua repercussão patrimonial, dentre outras características - a melhor alternativa consensual nem sempre é previsível ou possível de ser delineada de antemão por todos os envolvidos.

Assim, o procedimento a ser aplicável em tais casos não pode perder de vista as particularidades inerentes à espécie do conflito considerado. Com efeito, em muitos casos, algumas das partes envolvidas podem, em um primeiro momento, até mesmo se recusarem à busca da solução consensual, prejudicando 
a predisposição de todos os demais interessados nesse sentido. Além disso, há que se considerar que a própria escolha ou aceitação do mediador - ou agente facilitador do acordo - poderá se tornar um ponto de controvérsia, tornando ainda mais intrincado o procedimento.

Sob o ponto de vista de Lawrence Susskind, espera-se do mediador, em um conflito que envolve interesses públicos, que ele consiga convencer as partes a "virem para a mesa" e negociarem as regras do procedimento por meio do qual o acordo será buscado. Segundo o mencionado autor, espera-se, ainda, que o mediador, a partir do que for discutido pelas partes, seja o responsável por elaborar a minuta dos termos do acordo, apresentá-lo aos envolvidos e, após alcançado o consenso, monitorar a sua implementação. ${ }^{16}$

Além disso, o mediador deve ser o responsável por identificar as partes que ainda porventura não estejam "à mesa", mas precisariam estar em razão da natureza do conflito e dos interesses envolvidos. Incumbe ao profissional, ainda, a responsabilidade de aferir se as partes presentes constituem verdadeiros e suficientes representantes adequados daquelas que não participarão diretamente das negociações e discussões, mas serão afetadas por seu resultado.

A depender do objeto em discussão, a celebração do acordo somente pode ser possível a partir da assunção de compromissos provisórios e contingenciais, sobretudo quando paira insegurança sobre o que pode ou não acontecer a partir de determinado momento da execução do acordo (no caso das obrigações a serem assumidas por um ente público, pode-se exemplificar com a hipótese de drástica frustração de receita orçamentária).

Veja-se, portanto, que é possível vislumbrar, a partir do que foi exposto até aqui, significativas diferenças e particularidades entre o procedimento de mediação voltado para conflitos individuais bilaterais e aquele que deve ser aplicável aos conflitos coletivos, os quais são, por sua natureza, multipartes. Frise-se que a expressão parte, aqui utilizada no sentido de indivíduo ou pessoa jurídica interessada, não se confunde com o sentido processual de figurar como parte ativa ou passiva em ações coletivas. ${ }^{17}$

Não sem razão, as particularidades ora tratadas podem ser concebidas, à primeira vista, como dificuldades ou, ainda, como verdadeiros obstáculos à obtenção do consenso e à consequente celebração de um acordo com repercussões coletivas. Entretanto, não apenas o número de acordos celebrados em âmbito nacional, formalizados em termos de ajustamento de conduta, ${ }^{18}$ fornece uma perspectiva otimista para a análise, como também os relatos de casos de sucesso encontrados na literatura comparada, sobretudo na norte-americana. ${ }^{19}$

Assim, o alcance do consenso em conflitos coletivos, não obstante a sua inerente complexidade, não se trata, portanto, de utopia acadêmica, mas de um resultado desejável que pode ser aprimorado e potencializado com o aperfeiçoamento da técnica adequada. 


\section{ESPÉCIES DE CONFLITOS COLETIVOS E A ADEQUAÇÃO DA TÉCNICA}

A par do que foi exposto, não se descura da possibilidade de que, a depender das espécies de conflitos coletivos considerados, a conciliação ou a negociação entre as partes ou seus representantes sejam procedimentos suficientes e adequados para a obtenção do consenso. Pense-se, por exemplo, em uma negociação entre os sindicatos patronais e dos trabalhadores (relação trabalhista), em uma conciliação entre determinados consumidores lesados e a empresa responsável pela lesão (relação consumerista) ou entre pais de alunos de uma escola e a respectiva direção do estabelecimento em relação ao preço das mensalidades escolares (relação de prestação de serviços educacionais privados). É perfeitamente possível - como de fato ocorre - que o consenso seja alcançado em tais casos sem que quaisquer agentes intervenientes, sejam mediadores ou facilitadores, estejam presentes durante os atos do procedimento.

Por outro lado, imaginem-se, por exemplo, os conflitos decorrentes da pretensão de instalação de determinada usina hidrelétrica em um afluente de rio com população ribeirinha; ${ }^{20}$ de um município que não esteja prestando o ensino médio a todos os alunos que o pretendem cursar; do projeto de construção de uma penitenciária em área geográfica com grandes vulnerabilidades sociais; e da insuficiência de leitos de atendimento de urgência e emergência em um hospital público. A própria natureza de tais conflitos já nos evidencia, quase que intuitivamente, a dificuldade inerente à busca de uma solução ou de um consenso minimamente aceitável entre as pessoas e entes envolvidos. Para tais casos, não há dúvidas, a interveniência de um agente imparcial e comprometido com a busca dos interesses comuns entre as partes revela-se de crucial importância.

O papel do mediador é de tal modo diferenciado nos conflitos coletivos que, a partir das atribuições que lhe são conferidas, torna-se possível falar até mesmo em ativismo do mediador, ${ }^{21}$ como forma de conferir a necessária distinção e ênfase às atividades por ele exercida durante o procedimento. Esse denominado ativismo pode ser identificado precipuamente a partir das seguintes condutas: 1) adoção das medidas necessárias para garantir a equalização da qualidade de representação das partes à mesa; ${ }^{22} 2$ ) identificação dos interesses que porventura ainda não estejam representados; 3 ) coleta de informações e análises técnicas suficientes à análise qualificada das questões controversas (colheita conjunta de provas); 4) definição das partes que devem se reunir em cada ato do procedimento; 5) advertência às partes quanto a eventual comportamento que possa comprometer a integridade e a credibilidade do procedimento.

Em uma primeira análise, falar-se em ativismo do mediador pode parecer um contrassenso diante da imparcialidade que a rigor se espera de sua atuação. Contudo, as características acima elencadas bem ilustram que tal denominação se deve, em verdade, ao seu papel desempenhado visando a garantir a lisura, a idoneidade e o equilíbrio do procedimento. 
Um dos aspectos mais destacados da mediação que envolve direitos coletivos diz respeito à importância da interação face a face dos titulares ou de seus representantes. Por tal motivo, sustenta-se que o processo decisório desenvolvido por meio do procedimento de mediação relacionado, por exemplo, a políticas públicas, ${ }^{23}$ favorece os mecanismos de democracia participativa. ${ }^{24}$

Contudo, é preciso atentar para o fato de que nem todos os conflitos coletivos são mediáveis. E isso se deve não apenas em virtude da impossibilidade de obtenção de consenso em relação a determinadas questões, mas, sobretudo, porque as técnicas autocompositivas não são aplicáveis ou suficientes em alguns casos. ${ }^{25}$ Por exemplo, questões que envolvem questionamentos de ordem constitucional sobre o que se pode ou não fazer, definição de conteúdo de direitos fundamentais ou valores morais, determinação se pessoas físicas ou jurídicas podem ou não agir de determinada forma que dependeria de autorização legal expressa ou ainda quando há grande disparidade de poder de negociação entre as partes representadas, sem que haja reais possibilidades de equalizá-lo. ${ }^{26} \mathrm{Com}$ efeito, os processos decisórios dos poderes legislativo e judiciário revelam-se mais adequados em tais casos. Assim, vislumbra-se principalmente a possibilidade de utilização da mediação em conflitos coletivos nas hipóteses em que se discute alocação e distribuição de recursos ou ainda quando e como se executar obrigações de fazer.

Um questionamento que se impõe no contexto da análise da mediação em conflitos coletivos no direito brasileiro é quem poderá exercer o papel de mediador. Nos Estados Unidos, os requisitos para exercer a atividade de mediação, quando determinada por algum juízo ou tribunal, devem atender aos critérios do próprio juízo, estadual ou federal. A competência para legislar em matéria processual é concorrente entre os poderes legislativos estaduais e federal. No âmbito federal, o Uniform Mediation Act regulamenta a matéria, mas não trata dos requisitos para que um profissional exerça a atividade de mediação. Na maioria dos Estados, também não há uma regulamentação normativa específica, exceto quando os próprios tribunais estabelecem os requisitos a serem cumpridos em relação aos casos por eles encaminhados. ${ }^{27}$ Alguns Estados, por seu turno, exigem que o mediador possua alguma graduação específica, que conclua determinado número de horas de treinamento ou que tenha algum certificado de programa reconhecido. ${ }^{28}$

Quando se trata da mediação em âmbito extrajudicial, o mediador deve ser alguém que tenha credibilidade perante todas as partes envolvidas no conflito. Assim, todas elas devem ter a oportunidade de opinar a respeito do profissional que irá exercer a função. ${ }^{29} \mathrm{~A}$ principal dificuldade prática que se apresenta à efetiva utilização da mediação em conflitos coletivos no Brasil consubstancia-se, por ora, na ausência de profissionais com capacitação e formação específicas, embora já se tenha notícia de oferta de cursos voltados especificamente para esse fim. ${ }^{30}$ 
Impõe-se observar, outrossim, que, no ordenamento jurídico brasileiro, a Constituição da República de 1988 delineia o perfil institucional de órgãos públicos cujos integrantes, em virtude de sua formação profissional e atribuições funcionais, poderiam - e pelas razões acima expostas, seria desejável que o fizessem - desempenhar o papel de mediadores ou facilitadores nos conflitos que se lhes apresentassem no exercício das funções, tais como os membros do Ministério Público (art. 127), da Advocacia Pública (art. 131) e da Defensoria Pública (art. 134), sem prejuízo da possibilidade de contratação de mediadores privados, a depender da natureza do conflito e das partes envolvidas.

Vê-se, portanto, que o arcabouço normativo e as razões fáticas que fundamentam a busca pelas soluções consensuais dos conflitos estão mais do que evidenciadas no ordenamento jurídico brasileiro e sua moderna teoria e prática do direito processual. Identifica-se ainda a necessidade, entretanto, além de promoção da qualificação profissional específica, de se buscar melhor adequação da técnica aplicada às espécies de conflitos para os quais se pretende o alcance do consenso, sob pena de comprometermos os resultados passíveis de serem alcançados no plano do direito material, individual ou coletivo.

\section{CONCLUSÃO}

Foram apresentadas, no presente artigo, algumas reflexões a respeito da importância de se buscar a adequação das técnicas autocompositivas às espécies de conflitos nos quais se pretende aplicá-las. Essa preocupação se justifica não apenas em virtude do esforço normativo de promover a referida diferenciação em relação à natureza da relação jurídica considerada (se continuada e preexistente ao conflito ou se eventual e concomitante ao conflito), mas, sobretudo, em razão de suas repercussões sobre a própria efetividade do meio empregado.

Demonstrou-se, assim, que as atuais normas que disciplinam os meios autocompositivos de resolução de conflitos no direito brasileiro não oferecem parâmetros suficientes e adequados para que sejam aplicadas também aos conflitos coletivos, haja vista as peculiaridades inerentes às questões controversas que atingem as coletividades ou grupos de pessoas.

Nesse contexto, buscou-se problematizar o papel desempenhado pelo mediador nessas espécies de conflitos, bem como em que medida a postura do profissional poder-se-ia revelar imparcial diante de questões essenciais à obtenção do justo consenso. Além disso, evidenciou-se que as fases do procedimento autocompositivo, em especial a mediação, devem contemplar o esclarecimento de questões técnicas e a mobilização de diversos interessados que porventura ainda não estejam à mesa com vistas a obter o almejado consenso.

Os exemplos extraídos da experiência comparada demonstram que os meios autocompositivos de resolução de conflitos podem assumir importância e aplicação ainda mais extensas do que aquelas inicialmente vislumbradas a partir das normas que recentemente foram editadas no Brasil. Extrai-se que, assim 
como o microssistema do direito processual coletivo apresenta significativas distinções em relação às regras aplicáveis ao processo civil individual, constituindo ramo próprio de estudo, verifica-se que essa diferenciação também se aplica aos meios autocompositivos de resolução de conflitos. $O$ desafio que se descortina aos operadores do direito consubstancia-se na necessidade de adequação das técnicas aplicáveis, conforme a exigência da natureza do conflito. Espera-se que as reflexões ora apresentadas possam contribuir para esse esforço e para o necessário debate.

\section{REFERÊNCIAS}

DUKES, Franklin. Resolving Public Conflict: Transforming Community and Governance. New York: Manchester University Press, 2006.

FISHER, Roger; URY, William. Getting to Yes. London: Penguin Books, 1983.

FORESTER, John; SLITZEL, David. Beyond Neutrality: the Possibilities of Activist Mediation in Public Sector Conflicts. Negotiation Journal, United States, v. 5, n. 3, p. 251-264, 1989.

INNES, Judith. Consensus Building: Clarifications for the Critics. Planning Theori. Thousand Oaks: SAGE Publications, 2004.

MOORE, Christopher. The Mediation Process. San Francisco: Jossey-Bass, 2014.

MOSS, Daniel. Evaluating the Use of Mediation to Settle Land Use Disputes: a Look at the Provincial Facilitator's Office of Ontario. 1997. $82 \mathrm{f}$. Thesis (Master in City Planning) - Institute of Technology, Massachusetts, 1997.

NADER, Laura. Disputing without the Force of Law. Yale Law Journal, New Haven, v. 88, n. 5, p. 998-1021, 1979.

O’LEARY, Rosemary; NABATCHI, Tina; BINGHAM, Lisa. Assessing and Improving Conflict Resolution in Multiparty Environmental negotiations. International Journal of Organization Theory and Behavior, United States, v. 8, n. 2, p. 181-209, 2005.

PREIS, Mary. Mediation: Who Will Answer the Policy Questions? Maryland Bar Journal, Baltimore, v. 26, Oct. 1993.

REIS, Ludmila Costa. As ações coletivas e os limites democráticos à judicialização das políticas públicas sociais no Brasil. 2009. 154 f. Dissertação (Mestrado em Direito) - Faculdade de Direito da Universidade Federal de Minas Gerais, Minas Gerais, 2009.

RODRIGUES, Geisa de Assis. Ação Civil Pública e Termo de Ajustamento de Conduta: teoria e prática. Rio de Janeiro: Forense, 2006. 
SOUZA, Luciane Moessa de. Mediação de conflitos coletivos. Belo Horizonte: Fórum, 2012.

SUSSKIND, Lawrence. Multi-Party Public Policy Mediation: a Separate Breed. Dispute Resolution Magazine, v. 4, n.1, Fall 1997.

SUSSKIND, Lawrence; McKEARNAN, Sarah; THOMAS-LARMER, Jennifer. The Consensus Building Handbook: a Comprehensive Guide to Reaching Agreement. Thousand Oaks: SAGE Publications, 1999.

SUSSKIND, Lawrence. Environmental Mediation and the Accountability Problem. Vermont Law Review, South Royalton, v. 6, n. 1, p. 1-47, 1981.

THIBAU, Tereza Cristina Sorice Baracho. A legitimação ativa nas ações coletivas: um contributo para o estudo da substituição processual. 2003. $297 \mathrm{f}$. Tese (Doutorado em Direito) - Faculdade de Direito da Universidade Federal de Minas Gerais, Belo Horizonte, 2003.

ZEINEMANN, Robert. The Characterization of Public Sector Mediation. Environmental Law and Policy Journal, v. 24, p. 49-63, 2001.

1 Apesar de já se ter notícias sobre projetos de implantação de algumas varas especializadas no norte do país, tais como no estado do Amazonas. Disponível em: <http://www.ale.am.gov.br/2014/02/06/ amazonas-podera-ganhar-vara-de-acoes-coletivas-e-criminais-nas-relacoes-de-consumo-ate-marco/ $>$. Acesso em: 20 jul. 2016

2 Meta n $^{\circ}$ 6/CNJ do ano de 2014 para a Justiça Estadual e Justiça do Trabalho: Identificar e julgar, até $31 / 12 / 2014$, as ações coletivas distribuídas até $31 / 12 / 2011$, no $1^{\circ}$ grau e no TST, e até 31/12/2012, no $2^{\circ}$ grau.

3 META 6 - Priorizar o julgamento das ações coletivas: STJ, Justiça Estadual, Justiça Federal e Justiça do Trabalho - Identificar e julgar até 31/12/2016: 1) No STJ, 60\% dos recursos oriundos de ações coletivas distribuídas a partir de 01/01/2015; 2) Na Justiça Estadual, 60\% das ações coletivas distribuídas até $31 / 12 / 2013$ no $1^{\circ}$ grau, e $80 \%$ das ações coletivas distribuídas até 31/12/2014 no $2^{\circ}$ grau; 3) Na Justiça Federal, $100 \%$ das ações coletivas distribuídas até $31 / 12 / 2012$ no $1^{\circ}$ e $2^{\circ}$ graus; 4) Nos Tribunais Regionais e Juízes do Trabalho, as ações coletivas distribuídas até 31/12/2013 no $1^{\circ}$ grau e até $31 / 12 / 2014$ no $2^{\circ}$ grau; e 5) No Tribunal Superior do Trabalho, as ações coletivas distribuídas até 31/12/2013. Disponível em: <http://www.cnj.jus.br/corregedoriacnj/metas/609-gestao-planejamento-e-pesquisa/gestao-eplanejamento/gestao-e-planejamento-do-judiciario/metas-do-judiciario >. Acesso em: 20 fev. 2016.

4 Conforme previsão do item 1.1, alínea "i”, do Anexo I da Resolução CNJ n ${ }^{\circ} 125 / 2010$, com a redação dada pela Emenda n ${ }^{\circ}$ 2, de 08/03/2016.

5 ZEINEMANN, Robert. The characterization of public sector mediation. Environmental Law and Policy Journal, v. 24, p. 49, 2001.

6 Dentre as características que distinguem a mediação ambiental dos procedimentos que envolvem mediação entre particulares podem ser citadas: as disputas centram-se nas relações entre o homem e o meio ambiente, apresentam níveis elevados de complexidade e incerteza, afetam bens de uso comum, envolvem múltiplas partes e interesses contrapostos (cidadãos, empresários e industriais, agências governamentais, agentes políticos, associações não governamentais), implicam possibilidades de efeitos intergeracionais etc.

7 Op. cit., p. 50;

8 FORESTER, John; SLITZEL, David. Beyond neutrality: the possibilities of activist mediation in Public Sector Conflicts. Negotiation Journal, Unites States, v. 5, n. 3, p. 251-264, 1989; SUSSKIND, Lawrence. Environmental Mediation and the accountability problem. Vermont Law Review, South Royalton, v. 6, n. 1, p. 1-47, 1981.

9 FISHER, Roger; URY, William. Getting to Yes. London: Penguin Books, 1983. 
10 Detalhamento dos cursos oferecidos. Disponível em: <http://www.pon.harvard.edu/executive-education>. Acesso em: 30 jun. 2016.

11 Ar. 166, §4 "A mediação e a conciliação serão regidas conforme a livre autonomia dos interessados, inclusive no que diz respeito à definição das regras procedimentais".

12 De acordo com o Uniform Mediation Act, em vigor nos EUA, mediação significa "um processo no qual um mediador facilita a comunicação e a negociação entre partes para assisti-las no alcance de um acordo voluntário relativo à sua disputa". Sob o ponto de vista doutrinário, a mediação é concebida como "um processo de resolução de conflito no qual um terceiro mutuamente aceito pelas partes, que não tem autoridade para tomar decisões vinculantes, intervém em um conflito ou disputa para assistir as partes em prol da melhoria de seu relacionamento, aumentar a comunicação, e utilizar procedimentos de negociação e solução de problemas efetivos para alcançar entendimentos ou acordos voluntários e mutuamente aceitos em questões controversas" (MOORE, Christopher. The mediation process. San Francisco: Jossey-Bass, 2014. p. 20).

13 PREIS, Mary. Mediation: who will answer the policy questions? Maryland Bar Journal, Baltimore, v. 26, Oct. 1993.

14 SUSSKIND, Lawrence. Multi-party public policy mediation: a separate breed. Dispute Resolution Magazine, v. 4, n. 1, p. 4, Fall 1997.

15 No procedimento da negociação, Ury e Fisher intitularam de BATNA ("best alternative to a negotiated agreement" ou "melhor alternativa para um acordo negociado") o conteúdo mínimo de um acordo negociado que seja satisfatório para ambas as partes.

16 SUSSKIND, Lawrence. Multi-party..., op. cit., p. 5.

17 Sobre o tema, vide: THIBAU, Tereza Cristina Sorice Baracho. A legitimação ativa nas ações coletivas: um contributo para o estudo da substituição processual. 2003. 297 f. Tese (Doutorado em Direito) Faculdade de Direito da Universidade Federal de Minas Gerais, Belo Horizonte, 2003.

18 Para uma abordagem mais profunda e detalhada, vide: RODRIGUES, Geisa de Assis. Ação civil pública e termo de ajustamento de conduta: teoria e prática. Rio de Janeiro: Forense, 2006.

19 MOSS, Daniel. Evaluating the use of mediation to settle land use disputes: a loof at the Provincial Facilitator's Office of Ontario. 1997. 82 f. Thesis (Master in City Planning) - Institute of Technology, Massachusetts, 1997.; SUSSKIND, Lawrence; McKEARNAN, Sarah. Evaluating the use of mediation to resolve wetlands appeal cases: analysis and recommendations. Cambridge: CBI.; SUSSKIND, Lawrence; McKEARNAN, Sarah; THOMAS-LARMER, Jennifer. The consensus building handbook: a comprehensive guide to reaching agreement. Thousand Oaks: SAGE Publications, 1999; DUKES, Franklin. Resolving public conflict: transforming community and governance. New York: Manchester University Press, 2006.

20 Sobre as particularidades e complexidades da resolução de conflitos que envolvem questões ambientais, vide: O’LEARY, Rosemary; NABATCHI, Tina; BINGHAM, Lisa. Assessing and improving conflict resolution in multiparty environmental negotiations. International Journal of Organization Theory and Behavior, United States, v. 8, n. 2, p. 181-209, 2005.

21 ACTIVIST mediation: is that a contradiction in terms or a new opportunity? Planning Journal, Chicago, v. 79, p. 41, 2013; "ACTIVIST” Mediation, American Planning Association Magazine, p. 412013.

22 A possibilidade de o mediador adotar medidas para equalizar a representação das partes não é consenso entre os doutrinadores, mas trata-se de questionamento frequentemente levantado em casos nos quais se afiguram partes em evidente desvantagem social, financeira ou técnica. PREIS, Mary L. Mediation: who will answer the policy questions? Maryland Bar Journal, Baltimoore, v. 26, p. 26, 1993.

23 Sobre os mecanismos de controle de políticas públicas pela via judicial, vide: REIS, Ludmila Costa. As ações coletivas e os limites democráticos à judicialização das políticas públicas sociais no Brasil. 2009. 154 f. Dissertação (Mestrado em Direito) - Faculdade de Direito da Universidade Federal de Minas Gerais, Minas Gerais, 2009.

24 INNES, Judith. Consensus building: clarifications for the critics. Planning Theori. Thousand Oaks: SAGE Publications, 2004.

25 Conforme alerta Humberto Dalla, não se deve "imaginar que os métodos autocompositivos são a solução mágica para a crise do Estado-juiz ou mesmo que tenham capacidade para substituir integralmente a jurisdição". PINHO, Humberto. A mediação e o código de processo civil projetado. Disponível em: <https://www.academia.edu/4246510/A_MEDIACAO_E_O_CPC_PROJETADO_280612 >. Acesso em: 1 mar. 2016. 
26 Para uma abordagem sobre os casos em que a "força da lei" se faz mais adequada do que os meios autocompositivos, vide: NADER, Laura. Disputing without the force of Law, Yale Law Journal, New Haven, v. 88, n. 5, p. 998-1021, 1979.

27 Para informações mais detalhadas sobre as exigências de cada estado norte-americano, vide $<$ http:// www.mediationworks.com/medcert3/staterequirements.htm>. Acesso em: 1 mar. 2016.

28 PREIS, Mary L. Mediation: Who Will answer the policy questions? Maryland Bar Journal, Baltimore, v. 26, p. 26, 1993.

29 SOUZA, Luciane Moessa de. Mediação de conflitos coletivos. Belo Horizonte: Fórum, 2012. p. 115.

30 Vide o curso de Resolução Consensual de Conflitos Coletivos envolvendo Políticas Públicas, ofertado pela Escola Nacional de Mediação e Conciliação. Disponível em: < http://moodle.cead.unb.br/enam/ $\mathrm{mod} /$ book/view.php?id=83\&chapterid=73>. Acesso em: 28 jul. 2016.

\title{
ALTERNATIVE DISPUTE RESOLUTION IN COLLECTIVE CONFLICTS: REFLECTIONS ON THE SUITABLE TECHNIQUE IN FAVOUR OF EFFECTIVENESS
}

\begin{abstract}
This article proposes to examine the rules governing alternative dispute resolution methods in Brazilian Law and to confront them with their possible application to collective disputes. The aim is to discuss the application of conciliation, negotiation and mediation techniques to various kinds of conflict, given their distinctive features. The article shows that, considering the characteristics inherent to collective conflicts, legal professionals must search for appropriate technical solutions; otherwise the desired consensus results might be compromised. Thus, mediation is presented as the alternative dispute resolution technique potentially suitable for resolving collective conflicts, as long as the need to adapt such technique be considered.
\end{abstract}

Keywords: Conflict resolution. Alternative dispute resolution techniques. Collective conflicts.

Submetido: 8 ago. 2016

Aprovado: 27 set. 2016 